\title{
CHEMICAL AND STRUCTURAL HETEROGENEITIES IN TIG DISSIMILAR WELDED JOINTS OF FERRITIC STAINLESS STEELS AND MAGNESIUM ALLOYS WITH CU INTERLAYER
}

\author{
${ }^{1}$ Natanael SIMON, ${ }^{2}$ Olimpiu KARANCSI, ${ }^{1}$ Ion MITELEA, ${ }^{1}$ Corneliu Marius CRĂCIUNESCU \\ 1 University Politehnica Timişoara, Romania, EU, \\ ${ }^{2}$ Victor Babes University of Medicine and Pharmacy Timisoara, Romania, EU \\ natanael.simon@upt.ro, karancsi.olimpiu@umft.ro, ion.mitelea@upt.ro, corneliu.craciunescu@upt.ro
}

https://doi.org/10.37904/metal.2019.925

\begin{abstract}
The TIG welding process is well known for its advantages and exclusivity when it comes to weld materials such as Titanium, Magnesium, Aluminium, etc. which requires special conditions, therefore in this experiment we use TIG welding procedure to join two materials to two different base materials: $\mathrm{Cu}-(\mathrm{FM})$ on ferritic stainless steel-(BM); Mg-(FM) on Copper-(BM). In this paper are analysed intermetallic compounds and constituents formed in different zones of welded sample: HAZ of base material, fusion line, fusion zone, etc. To produce qualitative, braze-welded joints between dissimilar materials, we need to fully understand and take in consideration different factors. Obtained results are evaluated by optical microscopy, scanning electron microscopy and EDX-analyses.
\end{abstract}

Keywords: TIG welding, magnesium, ferritic stainless steel, intermetallic compounds, constituents

\section{INTRODUCTION}

The need for joining dissimilar metals arises from the complex functionality of many modern industrial applications. As manufacturers focus on reducing operational costs, search for increased mechanical and thermal properties and lightweight solutions for sectors like aerospace and automotive industries, multiple material combinations are increasingly being used for many products [1].

Several techniques exist for joining dissimilar materials [2]. However, there are many difficulties associated with the welding of dissimilar metals, which arise from metallurgical incompatibilities, like the formation of brittle phases, segregation of high and low melting phases due to chemical mismatch, and possibly large residual stresses from physical mismatch [3].

Mg alloys have become a competitive new light structural material. It is now being widely used in electronic communication, automotive, and aerospace. Steel materials will continue to occupy a dominant position in the application of industrial production with the successful development of high-strength steel [4].

The challenges of bonding immiscible $\mathrm{Mg} / \mathrm{steel}$ dissimilar metals are no Fe-Mg intermetallic compounds and little solid solubility in the Mg-Fe system, and differences in the physical and chemical properties of $\mathrm{Mg}$ and $\mathrm{Fe} . \mathrm{Mg} / \mathrm{steel}$ welds are not like the $\mathrm{Al} / \mathrm{steel}$ or $\mathrm{Al} / \mathrm{Mg}$ joint. Many $\mathrm{Fe}-\mathrm{Al}$ compounds are detected in the $\mathrm{Al} / \mathrm{Fe}$ joint, which influences the Al/Fe joint performance. However, there was no intermetallic compound (IMC) forming in the $\mathrm{Mg} / \mathrm{Fe}$ joint, and little solid solubility in the Mg-Fe system. Hence, knowing how to obtain an interface layer with a certain thickness is the key to the bonding of immiscible Mg/Steel dissimilar metals [5].

Promoting interfacial reaction could form an $\mathrm{Mg} /$ steel interface layer and obtain an effective $\mathrm{Mg} / \mathrm{steel}$ joint. Currently, the research on joining $\mathrm{Mg} / \mathrm{steel}$ mainly focuses on the following aspects. First, the elements of the interface layer mainly come from the base metal or by adding alloy elements. Therefore, designing different types of interface layers could be achieved by choosing different components of the base metal and suitable alloy elements, such as, Mg base filler wires (AZ31, AZ61 and AZ91) and interlayer (Al, Cu, Ni, Cu-Zn foil layers or $\mathrm{Ni}, \mathrm{Zn}, \mathrm{Sn}$ coatings, et al.) [4,6,7]. 
In this context, the research was focused on the problems occurring in the interface areas of the joints made of ferritic stainless steel with a copper alloy and of copper alloy with a magnesium alloy. Obtained results are evaluated by optical microscopy, scanning electron microscopy and EDX-analyses.

\section{EXPERIMENTAL PROCEDURE}

The materials used were ferritic stainless-steel sheets and pure copper sheets (30x30 mm). AZ31 magnesium wire and a T2 pure copper wire were used as filler materials. AZ31 magnesium alloy was chosen due to its good rolling capabilities. Before welding, the oil on substrates (Cu-T2) surface was removed by a wire brush and acetone. The nominal alloying elemental compositions of the materials studied are shown in Table 1. The welding parameters and mechanical properties are discussed in a previous research [8].

Table 1 Chemical composition of base and filler (wt\%)

\begin{tabular}{|c|c|c|c|c|c|c|c|c|c|c|c|c|c|}
\hline \multirow{2}{*}{ Material } & \multicolumn{13}{|c|}{ Elements } \\
\hline & $\mathbf{C}$ & $\mathrm{Fe}$ & $\mathrm{Cr}$ & Mn & Mg & $\mathrm{Ni}$ & $\mathbf{S}$ & $\mathrm{Zn}$ & Al & $\mathbf{P}$ & $\mathrm{Cu}$ & Si & 0 \\
\hline Ferritic steel W1.4713 & 0.1 & rest & 7.1 & 0.68 & - & - & 0.011 & - & 0.72 & 0.026 & - & 0.74 & - \\
\hline$M g-A Z 31$ & - & 0.005 & - & 1.0 & rest & 0.005 & - & 1.3 & 3.5 & - & 0.01 & 0.05 & - \\
\hline T2 Copper & - & - & - & - & - & 0.021 & - & 0.025 & - & - & rest & - & 0.034 \\
\hline
\end{tabular}

After welding, the welded joints were ground with abrasive paper, mechanically polished with a final polishing step, comprising use of a $0.3 \mu \mathrm{m}$ diamond paste. Macro - and microstructural characterizations of welded samples were performed on their cross-sections by using Scanning Electron microscopy. The chemical compositions were examined by EDS (energy dispersive spectrometry) technique.

\section{RESULTS AND DISCUSSIONS}

In Figures 1a, b, the macroscopic appearance of the brazed joints between copper to ferritic stainless steel and magnesium alloy to copper are presented. Both images highlight the profile of the weld seam, resulting from the solidification, and the width of the heat-affected zone (HAZ). At the same time, it is noted that there are no weld defects, nor cracks, inclusions of slag or porosity.
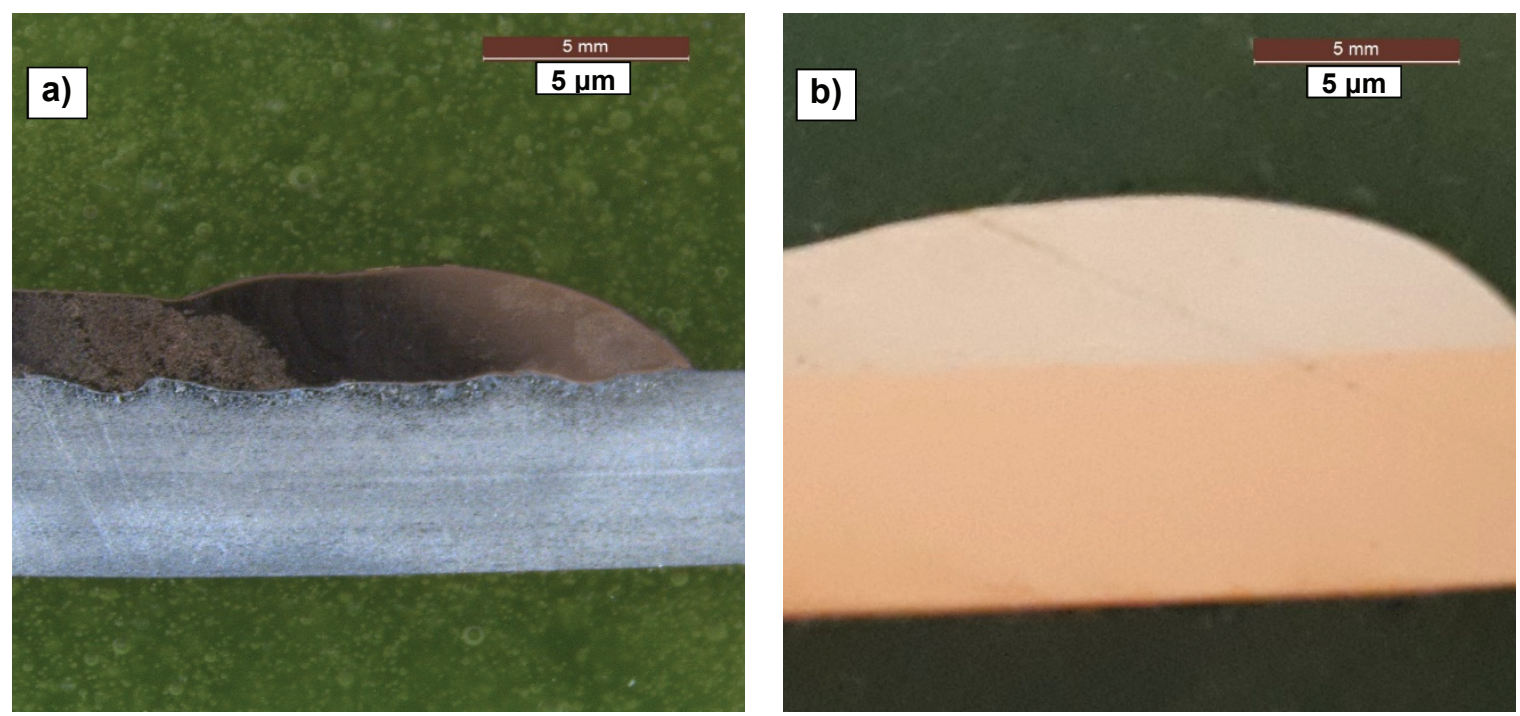

Figure 1 Macrografic images of the brazed joints: a) ferritic steel W1.4713 + T2 Copper; b) Mg-AZ31 + T2 copper 
Figure $\mathbf{2 a}$ and $\mathbf{2 b}$, shows SEM micrographs at the interface between $\mathrm{Cu}$ and the stainless steel. The curve interface suggests the steel is melted during weld-brazing. As expected, the structure of the deposited metal will not be influenced only by the metallurgical particularities of the filler material, considering the degree of dilution, and that of the base material. Since the ferritic stainless steel does not have polymorphic transformations, it is not possible to finish the granulation in the HAZ, and inside the large grains, it forms an acicular bainite structure.

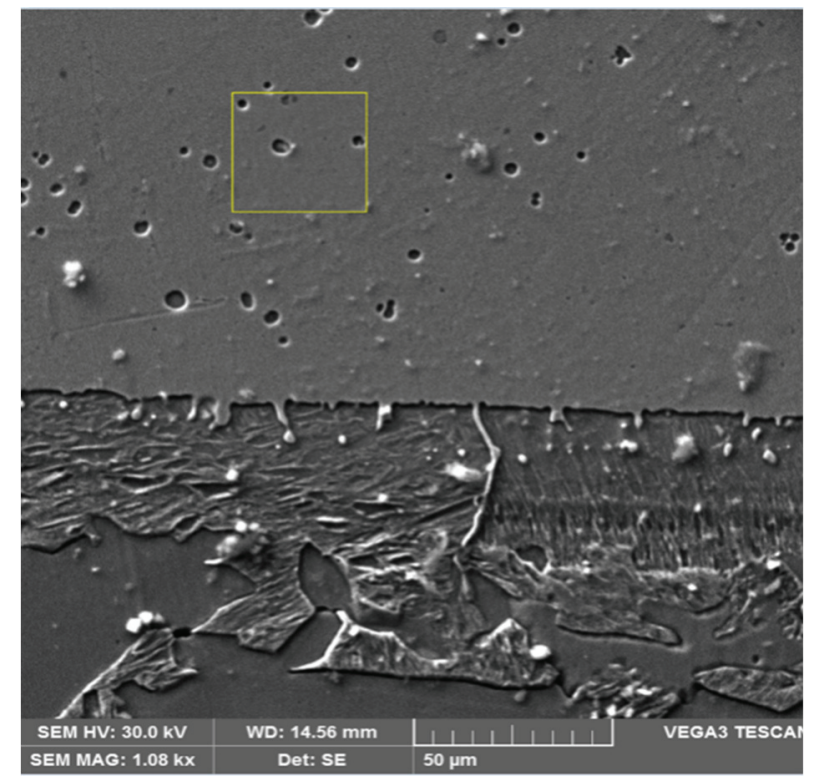

-a-

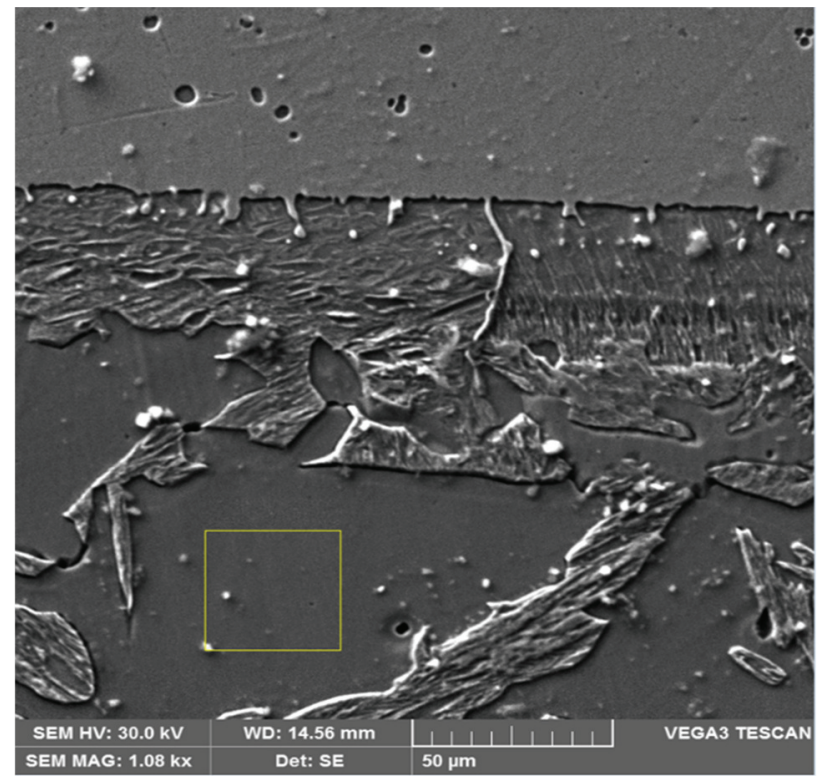

-b-

Figure 2 Stainless steel-copper interface micrograph with location of the chemical composition investigation area: $\mathrm{a}$ - in the vicinity of $\mathrm{Cu}$; $\mathrm{b}$ - near ferritic steel

The results of EDX analysis (Tables $\mathbf{2 a}$ and $\mathbf{2 b}$ ) highlight the following:

- $\quad$ an increase in oxygen in the adjacent portion of copper due to its high affinity to oxygen;

- the presence of iron in the concentration of approx. $3 \mathrm{wt} \%$ in copper, due to dilution;

- burning manganese in the adjacent portion of ferritic steel.

Table 2 Chemical heterogeneities of the ferritic steel - copper interface:

a) the area in the neighbourhood of $\mathrm{Cu}$ (Figure 2a)

\begin{tabular}{|c|c|c|c|c|}
\hline Element & Series & $(\mathrm{wt} \%)$ & $(\mathrm{at} \%)$ & $\boldsymbol{\sigma}(\mathrm{wt} \%)$ \\
\hline Iron & $\mathrm{K}$ & 92.55 & 90.71 & 2.38 \\
\hline Chromium & $\mathrm{K}$ & 5.90 & 6.21 & 0.18 \\
\hline Aluminum & $\mathrm{K}$ & 0.78 & 1.59 & 0.07 \\
\hline Silicon & $\mathrm{K}$ & 0.76 & 1.48 & 0.07 \\
\hline
\end{tabular}

b) the area near the ferritic steel (see Figure $\mathbf{2 b}$ )

\begin{tabular}{|c|c|c|c|c|}
\hline Element & Series & $(\mathrm{wt} \%)$ & $($ at $\%)$ & $\boldsymbol{\sigma}(\mathrm{wt} \%)$ \\
\hline Copper & $\mathrm{K}$ & 93.29 & 83.99 & 2.29 \\
\hline Oxygen & $\mathrm{K}$ & 3.58 & 12.80 & 0.62 \\
\hline Iron & $\mathrm{K}$ & 3.13 & 3.21 & 0.11 \\
\hline
\end{tabular}

According to Figure 3, where the microstructure of the magnesium-copper alloy bonding zone is reproduced, the Mg-alloy material stitch portion of the alloy has a microstructure consisting of massive $\alpha$-Mg but contains some dispersed particles in a-Mg grains, which is a typical structure of AZ31B Mg fusion welds. 


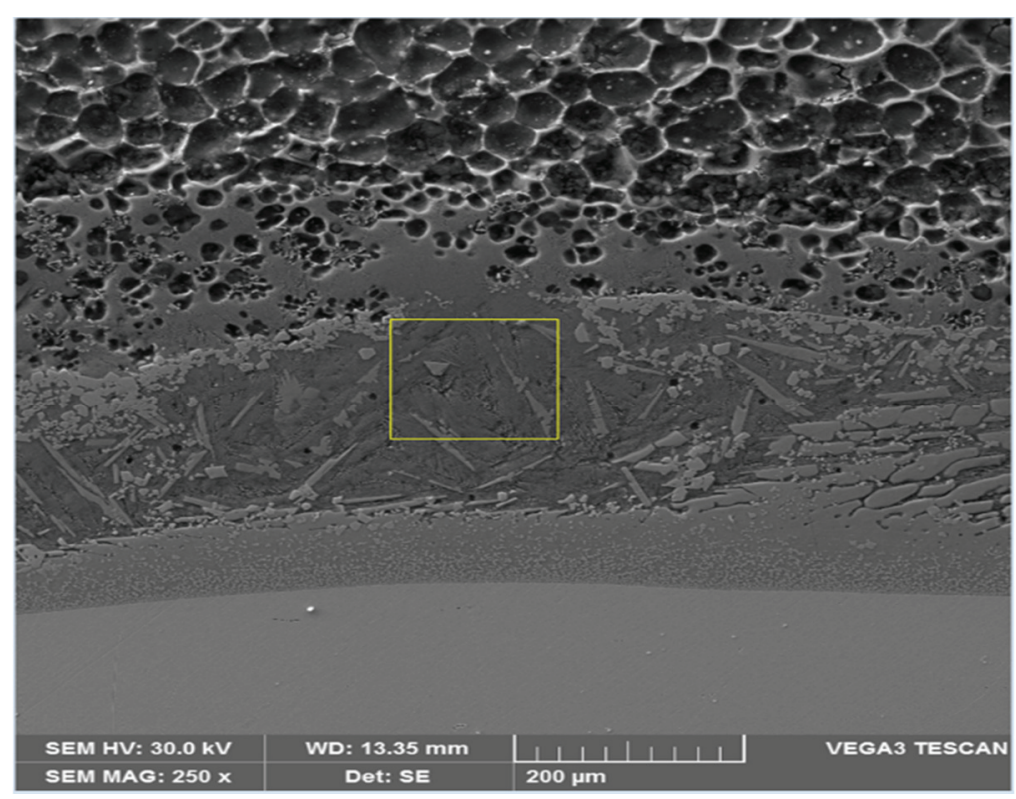

Figure 3 Interface microstructure between Mg alloy and Cu with EDX analysis area indication

EDX analyzes (Figure 3 and Table 3 ) highlight the formation of a new alloy in the bonding area, a phenomenon that proves good metallurgical compatibility between the two TIG welded materials.

Table 3 Chemical composition of the joint resulting from the heterogeneous welded $\mathrm{Cu}$ - alloy of $\mathrm{Mg}$ (see yellow area in Figure 3)

\begin{tabular}{|c|c|c|c|c|}
\hline Element & Series & $(\mathrm{wt} \%)$ & $($ at $\%)$ & $\boldsymbol{\sigma}(\mathrm{wt} \%)$ \\
\hline Manganese & $\mathrm{K}$ & 0.11 & 0.06 & 0.03 \\
\hline Aluminum & $\mathrm{K}$ & 3.95 & 4.12 & 0.21 \\
\hline Silicon & $\mathrm{K}$ & 0.64 & 0.64 & 0.06 \\
\hline Copper & $\mathrm{K}$ & 37.16 & 16.45 & 0.86 \\
\hline Magnesium & $\mathrm{K}$ & 36.98 & 42.80 & 1.97 \\
\hline Oxygen & $\mathrm{K}$ & 19.95 & 35.08 & 2.34 \\
\hline Calcium & $\mathrm{K}$ & 1.22 & 0.85 & 0.06 \\
\hline
\end{tabular}

\section{CONCLUSION}

This study could be a helpful document to understand the microstructure and the performance of an $\mathrm{Mg} /$ stainless steel TIG welding, with an intermediate layer of $\mathrm{Cu}$.

$\mathrm{Al}-\mathrm{Mg}$ intermetallic compounds were generated in the irregular shaped region in the welded zone.

Because of the dilution phenomenon, the iron is present in concentrations of approx. 3 wt $\%$ in copper welding and magnesium and copper participate in similar concentrations (about $37 \%$ ) in welding adjacent to the magnesium alloy.

\section{REFERENCES}

[1] DARWISH, S.M. Analysis of weld-bonded dissimilar materials. International Journal of Adhesion and Adhesives. 2004. vol. 24, Issue 4, pp. 347-354. 
[2] KAH, P. and MARTIKAINEN, M.S.J. Trends in joining dissimilar metals by welding. Applied Mechanics and Materials. 2014. vol. 440, pp. 269 - 276.

[3] SUN, Z. and KARPPI, R. The application of electron beam welding for the joining... J. Mater. Process. Technol. 1996, vol. 59, no. 3, pp. 257-267.

[4] SONG, G. LI, T., YU, J. and LIU, L. A Review of bonding immiscible Mg/steel dissimilar metals. Materials. 2018. vol. 11, pp. 1-25.

[5] AIZAWA, T., HASEHIRA, K., I. and NISHIMURA, C. Solid state synthesis of non-equilibrum phase in Mg-Co and Mg-Fe systems via bulk mechanical alloying. Mater. Trans. 2003. vol. 44, pp. 601-610.

[6] CASAlinO, G., GUGLIELMI, P., LORUSSO, V.D., MORTELLO, M., PEYRE, P. and SORGENTE, D. Laser offset welding of AZ31B magnesium alloy to 316 stainless steel. Journal of Materials Processing Technology. 2017. vol. 242, pp. 49-59.

[7] WAHBA, M. and KATAYAMA, S. Laser welding of AZ31B magnesium alloy to Zn-coated steel. Materials \& Design. 2012. vol. 35, pp. 701-706.

[8] SIMON, N., MITELEA, I., BURCA, M. and UTU, I.D. The particularities of the CMT braze-welding process between ferritic stainless steel - magnesium alloy. IOP Conference Series Materials Science and Engineering. 2018. vol. 416, pp. 1-7. 